\title{
A INFLUÊNCIA DO CAMPO MAGNÉTICO NA GERMINAÇÃO DE VEGETAIS
}

\author{
Fábio Henrique Silva Sales \\ Professor do Departamento de Física do Instituto Federal de Educação, Ciência e Tecnologia \\ do Maranhão (IFMA) \\ fsales@ifma.edu.br \\ Dayanna Gomes Santos \\ Acadêmica do Curso de Psicologia da Universidade Federal do Maranhão (UFMA) \\ dadabiu@ hotmail.com \\ Luana Lopes Padilha \\ Acadêmica do Curso de Ciências Biológicas e da Saúde da Universidade Federal do \\ Maranhão (UFMA) \\ luanapadilha13@hotmail.com
}

\section{RESUMO}

Atualmente pesquisa-se e estuda-se bastante o fenômeno eletromagnético nas mais variadas áreas do conhecimento, desde os efeitos do campo magnético gerado por aparelhos celulares a pesquisas envolvendo campos magnéticos artificiais em vegetais e na Biofísica. Tudo isto porque o discurso do desenvolvimento auto-sustentável é o alvo do momento, utilizar os recursos do meio sejam eles vegetais ou animais, de forma consciente, de modo que as gerações futuras possam desfrutar dos mesmos assim como nós. Outro campo de importância é o das pesquisas agrícolas, em que as descobertas e o desenvolvimento de técnicas serão sempre bem-vindos, em virtude das constantes agressões sofridas pelo meio, sejam elas de natureza antrópica, como as queimadas e o desmatamento, ou natural, como as pragas que atacam as plantações. Diante disso, torna-se interessante, estudos a respeito dos fatores que influenciam ou "potencializem" a germinação de sementes e o crescimento de vegetais, objetivando a recuperação de áreas até então inutilizadas. Com tal finalidade desenvolveu-se este Projeto de Pesquisa, cultivando algumas amostras de alface em laboratório, esperando-se que o campo magnético gerado pelo solenóide, atuasse sobre os íons que compõem a seiva bruta, facilitando assim a sua subida e consequentemente a aceleração do crescimento do vegetal.

PALAVRAS-CHAVE: campo magnético, germinação, vegetais.

\section{THE INFLUENCE OF THE MAGNETIC FIELD IN THE GERMINATION OF VEGETABLES}

\begin{abstract}
Now it is researched and it is studied plenty the electromagnetic phenomenon in the most varied areas of the knowledge, from the effects of the magnetic field generated by cellular apparel to you research involving artificial magnetic fields in vegetables and in the Biophysics. Everything this because the speech of the solemnity-maintainable development is the objective of the moment, to use the resources of the is half them vegetables or you
\end{abstract}


encourage, in a conscious way, so that the future generations can enjoy the same ones as well as us. Another field of importance is it of the agricultural researches, in that the discoveries and the development of techniques will always be welcome, because of the constants suffered aggressions for the middle, be them of nature antropic, as the burning and the deforestation, or natural, as the curses that attack the plantations. Before that, he/she becomes interesting, studies regarding the factors that influence or "potentiate" the germination of seeds and the growth of vegetables, aiming at the recovery of areas until then disabled. With such a purpose he/she grew this Project of Research, cultivating some lettuce samples in laboratory, being waited that the magnetic field generated by the solenoid, it acted on the ions that they compose the rude sap, facilitating like this his/her ascent and consequently the acceleration of the growth of the vegetable.

KEY-WORDS: Magnetic field, Germination, Vegetable. 


\section{A INFLUÊNCIA DO CAMPO MAGNÉTICO NA GERMINAÇÃO DE VEGETAIS}

\section{INTRODUÇÃO}

Atualmente, fala-se muito em desenvolvimento auto-sustentável, utilizar os recursos do meio de forma consciente e preservar para que as futuras gerações ainda possam usufruir deles, entre suas metas destacam-se: a preservação de recursos minerais, animais, vegetais, além da recuperação de áreas devastadas pela ação do ambiente ou até mesmo pela ação antrópica.

A finalidade deste trabalho foi usar o magnetismo como alternativa para acelerar o crescimento de espécies vegetais, inicialmente a alface, através da submissão da planta a um campo magnético fraco gerado por um solenóide como sendo uma futura técnica que possa vir a ser utilizada para se quebrar a dormência de sementes e aumentar o número de germinações.

Foram feitas experiências em laboratório simulando o cultivo de leguminosas e, diariamente, era realizada a biometria para a análise e conclusão dos resultados.

\section{ELETROMAGNETISMO}

Eletromagnetismo estuda as propriedades elétricas e magnéticas da matéria e, em especial, as relações que se estabelecem entre elas.

A existência de forças naturais de origem elétrica e magnética fora observada em contextos históricos independentes, mas só na primeira metade do século XIX um grupo de pesquisadores conseguiu unificar os dois campos de estudo e assentar os alicerces de uma nova concepção da estrutura física dos corpos.

No final do século XVIII Charles-Augustin de Coulomb e Henry Cavendish haviam determinado as leis empíricas que regiam o comportamento das substâncias eletricamente carregadas e o dos ímãs. Embora a similaridade entre as características dos dois fenômenos indicasse uma possível relação entre eles, só em 1820 se obteve prova experimental dessa relação, quando o dinamarquês Hans Christian Oersted, ao aproximar uma bússola de um fio de arame que unia os dois pólos de uma pilha elétrica, descobriu que a agulha imantada da bússola deixava de apontar para o norte, orientando-se para uma direção perpendicular ao arame.

Pouco depois, André-Marie Ampère demonstrou que duas correntes elétricas exerciam mútua influência quando circulavam através de fios próximos um do outro. Apesar disso, até a publicação, ao longo do século XIX, dos trabalhos do inglês Michael Faraday e do escocês James Clerk Maxwell, o eletromagnetismo não foi e nem começou a ser considerado um autêntico ramo da física.

Os fenômenos eletromagnéticos são produzidos por cargas elétricas em movimento. A carga elétrica, assim como a massa, é uma qualidade intrínseca da matéria e apresenta a particularidade de existir em duas variedades, convencionalmente denominadas positiva e negativa. A unidade elementar da carga é o elétron, partícula atômica de sinal negativo, embora sua magnitude não resulte em entidade suficiente para cálculos macroscópicos normais. Como unidade usual de carga usa-se então o coulomb; o valor da carga de um elétron equivale a 1,60 x 10-19 coulombs. 
Duas cargas elétricas de mesmo sinal se repelem, e quando de sinais contrários se atraem. A força destas interações é diretamente proporcional a sua quantidade de carga e inversamente proporcional ao quadrado da distância que as separa. Para explicar a existência dessas forças adotou-se a noção de campo elétrico criado em torno de uma carga, de modo que a força elétrica que vai atuar sobre outra carga distanciada da primeira corresponde ao produto da quantidade de carga desta primeira por uma grandeza chamada intensidade de campo elétrico. A energia que este campo transmite à unidade de carga chama-se potencial elétrico e geralmente se mede em volts.

O eletromagnetismo é muito usado na construção de geradores de energia elétrica, dentre estes se destacam os alternadores ou geradores de corrente alternada, que propiciam maior rendimento que os de corrente contínua por não sofrerem perdas mediante atrito. A base do alternador é o eletroímã, núcleo em geral de ferro doce e em torno do qual se enrola um fio condutor revestido de cobertura isolante. $\mathrm{O}$ dispositivo gira a grande velocidade, de modo que os pólos magnéticos mudam de sentido e induzem correntes elétricas que se invertem a cada instante. Com isso, as cargas circulam várias vezes pela mesma seção do condutor. Os eletroímãs também são utilizados na fabricação de elevadores e instrumentos cirúrgicos e terapêuticos. Seu uso abrange diversos campos industriais, uma vez que os campos que geram podem mudar de direção e de intensidade.

\section{CAMPO MAGNÉTICO}

Campo magnético é uma região do espaço onde se manifesta o magnetismo, através das chamadas ações magnéticas. Estas ações são verificadas à distância e apenas algumas substâncias são influenciadas pelo campo magnético, como os materiais ferrosos. Estas substâncias são chamadas de ferromagnéticas.

Quando uma corrente elétrica atravessa um fio condutor, cria em torno de se um campo magnético. Este efeito foi verificado pela primeira vez por Hans Christian Orsted em abril de 1820 .

Nesse estudo científico o solenóide (Figura 1), que é um condutor enrolado em espiral foi usado para gerar um campo magnético fraco de 0,60mT. As linhas de força do campo magnético produzido por um solenóide são idênticas aos do campo magnético produzido por um ímã.

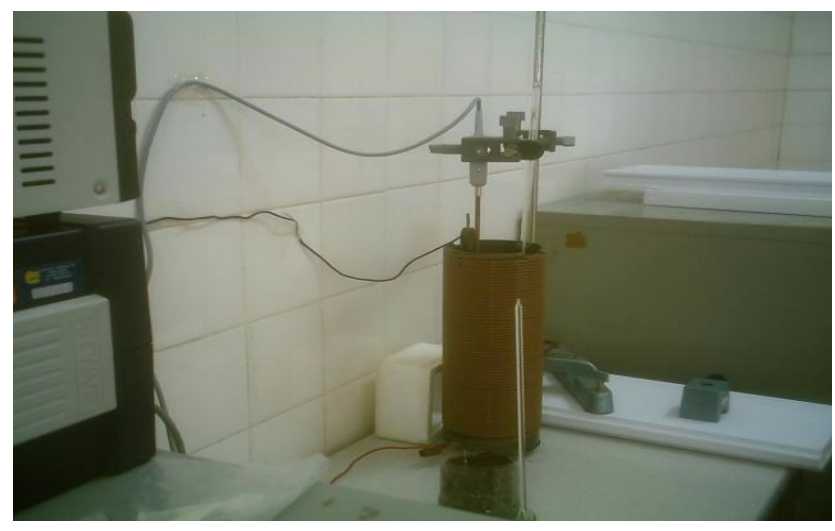

Figura 1 - Solenóide. 
O vetor, no centro da espira, tem módulo dado por:

$$
\mathbf{B}=(\boldsymbol{\mu o} . \mathbf{N . i}) / \mathbf{L}
$$

(equação 01)

Onde $\mathbf{B}$ é o campo magnético, $\boldsymbol{\mu o}$ é o coeficiente de permeabilidade magnética no vácuo, $\mathbf{N}$ é o número de espiras, i a corrente que percorre a espira e $\mathbf{l}$ é o comprimento do solenóide.

Os materiais eletromagnéticos são constituídos por um número muito grande de pequenos ímãs elementares que sem a influência do campo magnético encontram-se totalmente desordenado. Assim, quando sob a influência do campo magnético fraco gerado pelo solenóide, as sementes de alface passam a ter seus íons da seiva bruta ordenados, favorecendo na sua germinação.

\section{MATERIAIS E MÉTODOS}

O solenóide foi o principal aparelho utilizado no estudo, produzindo um campo magnético fraco através da corrente elétrica.

Além do solenóide, usou-se um voltímetro (Figura 2), aparelho responsável pela medição da voltagem ou ddp (diferença de potencial) entre os terminais do campo, um teslômetro (Figura 3), aparelho que mede a intensidade do campo magnético e materiais adicionais como balança e proveta para medir o volume de água e o microscópio eletrônico, responsável pela análise mais minuciosa da germinação das sementes de alface. As temperaturas externas e internas dos solenóides também foram monitoradas através de termômetros eletrônicos.

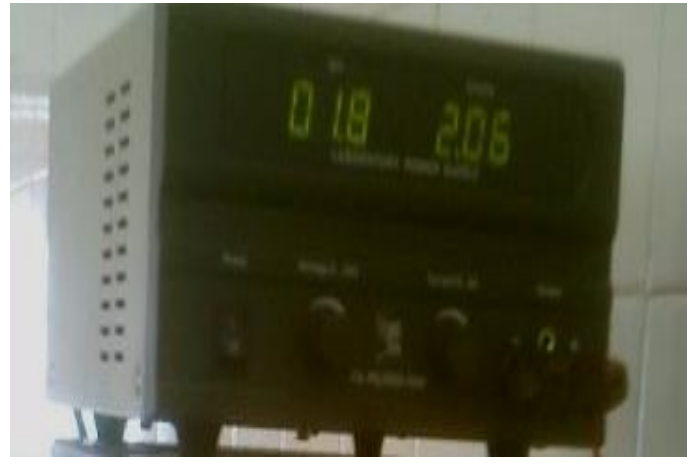

Figura 2 - Voltímetro.

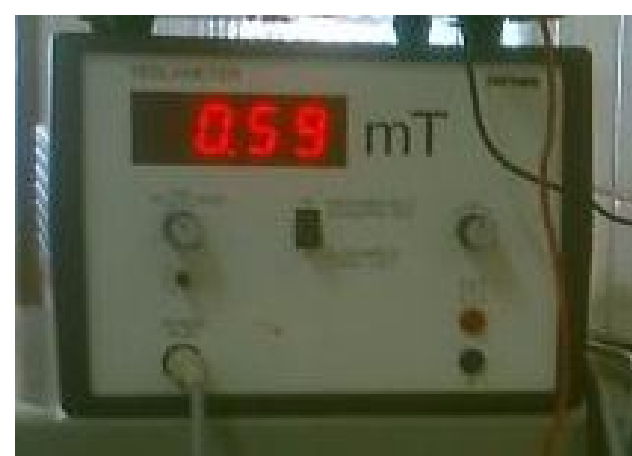

Figura 3 - Teslômetro.

Para todas as amostras, convencionou-se a formação de grupos teste e controle. O primeiro sendo a amostra com sementes sob a influência do campo magnético e, o segundo sendo a amostra sem essa influência. Em ambos os grupos foram plantados, simultaneamente, quarenta sementes de alface e usou-se $118 \mathrm{~g}$ de Húmus de minhoca e $10 \mathrm{ml}$ de água. Depois se esperou que elas germinassem para se comparar o tempo e o número de germinações de cada amostra. Na Figura 4 tem-se a representação da montagem do experimento. 


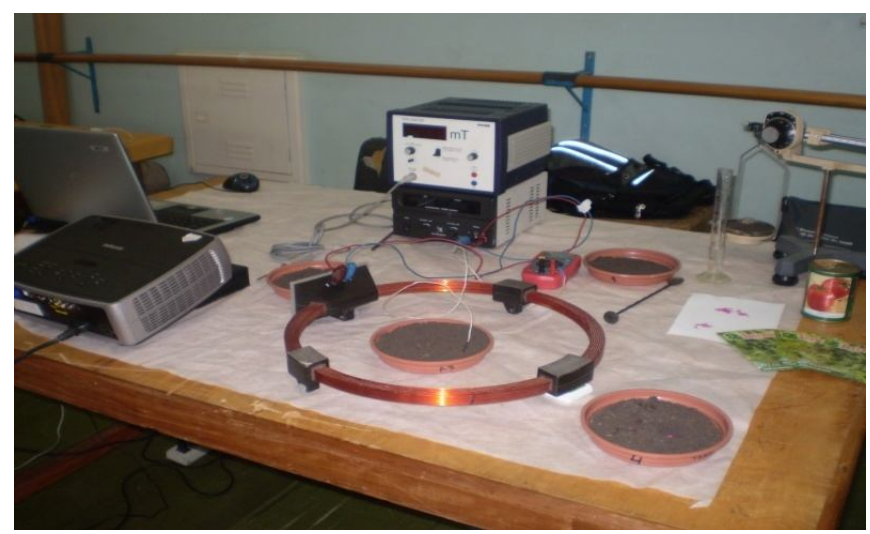

Figura 4 - Experimento montado.

\section{ENSAIOS}

Utilizou-se a amostra de quarenta pés de alface, os quais foram submetidos ao campo magnético médio de 0,60 mT constituindo, assim, o grupo teste; e, quarenta pés de alface foram submetidos a condições normais, sem o campo magnético formando, assim, o grupo controle. Os dados foram colhidos diariamente (biometria) e, então, utilizados para posteriores análises.

Os ensaios realizados, inicialmente, fora utilizado o sentido do campo de baixo para cima, durante um período de cinco dias. Cada ensaio durava em média um período de cinco dias, no qual eram realizadas biometrias diárias em cada amostra para se acompanhar o número de germinações de cada grupo observado. Posteriormente, usou-se o campo magnético no sentido de cima para baixo.

\section{ENSAIOS}

Utilizou-se a amostra de quarenta pés de alface, os quais foram submetidos ao campo magnético médio de 0,60 mT constituindo, assim, o grupo teste; e, quarenta pés de alface foram submetidos a condições normais, sem o campo magnético formando, assim, o grupo controle. Os dados foram colhidos diariamente (biometria) e, então, utilizados para posteriores análises.

Os ensaios realizados, inicialmente, fora utilizado o sentido do campo de baixo para cima, durante um período de cinco dias. Cada ensaio durava em média um período de cinco dias, no qual eram realizadas biometrias diárias em cada amostra para se acompanhar o número de germinações de cada grupo observado. Posteriormente, usou-se o campo magnético no sentido de cima para baixo.

\section{ANÁLISE E DISCUSSÃO DOS RESULTADOS}

Todas as baterias realizadas foram tabuladas, contendo os dados referentes às análises, pôdese analisar e discutir a variação da intensidade de corrente, do campo magnético e da voltagem em cada bateria realizada e principalmente verificar a diferença de germinações de 
um grupo para outro, fazendo uma analogia com o sentido do campo magnético. Constatando assim que este número variava conforme o seu sentido.

Se por exemplo, o sentido do campo tivesse de cima para baixo, o número de germinações do grupo controle era sempre superior ao número de germinações do grupo teste. Agora, se o campo tivesse direcionado de baixo para cima, o grupo teste superava o grupo controle.

Além disso, alteramos de uma etapa para outra o tipo de corrente utilizada. Nas primeiras baterias, usamos a corrente contínua (direção e sentido constantes), como fonte geradora do campo magnético e nas baterias posteriores a corrente alternada (direção, sentido e intensidade variáveis). Com esta alternância, pudemos constatar que o número de germinações ocorridas com a corrente alternada foi superior ao da contínua, devido ao fato de a força de atracação (força gerada no condutor quando o mesmo é percorrido por corrente elétrica) no solenóide de corrente alternada ser superior àquela verificada no solenóide de corrente contínua, considerando seus cursos iguais.

Com o campo magnético voltado para baixo, percebe-se que as sementes só germinam no primeiro dia após serem plantadas. Tomando como referência este ensaio para representar os resultados de todos os outros ensaios, o efeito encontrado foi que tanto o grupo teste quanto o grupo controle germinaram no mesmo dia, mas o número de germinações do primeiro foi menor que a do segundo com 30 germinações do grupo controle contra 6 germinações do grupo teste (Figuras 5 e 6). Esta biometria está representada na Tabela 1.

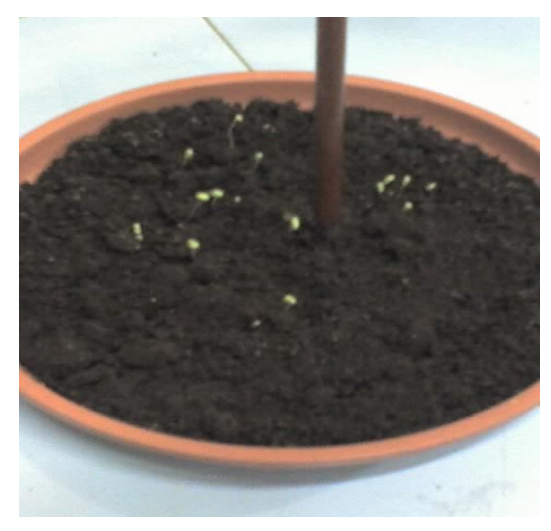

Figura 5 - Geminações do grupo teste com o campo magnético voltado para baixo.

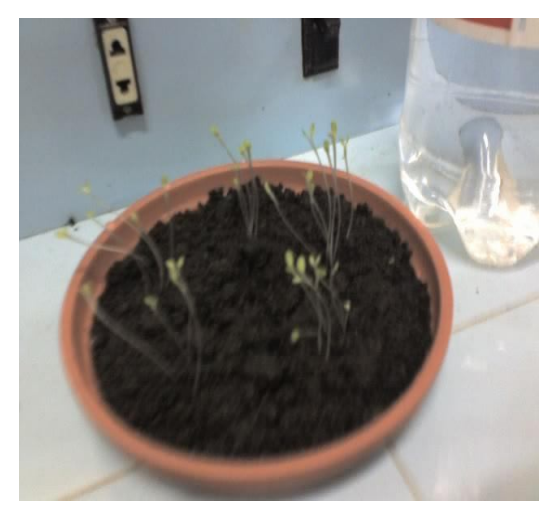

Figura 6 - Geminações do grupo controle o campo magnético voltado para baixo.

Tabela 1. Experimento com o campo magnético orientado "de cima para baixo"

\begin{tabular}{|c|c|c|}
\hline Dias & $\begin{array}{c}\text { Número de } \\
\text { germinações do } \\
\text { experimento sem o } \\
\text { campo magnético }\end{array}$ & $\begin{array}{c}\text { Número de } \\
\text { germinações do } \\
\text { experimento com o } \\
\text { campo magnético }\end{array}$ \\
\hline Início & 0 & 0 \\
\hline $1^{\circ}$ dia & 1 & 1 \\
\hline $2^{\circ}$ dia & 19 & 6 \\
\hline $3^{\circ}$ dia & 29 & 6 \\
\hline $4^{\circ}$ dia & 30 & 6 \\
\hline
\end{tabular}


Enquanto que, com o campo magnético voltado para cima, observa-se que também os dois grupos tiveram suas germinações juntos no segundo dia após serem plantados, e o efeito encontrado foi de vantagem para o grupo que estava sob a influência do campo magnético, no qual ocorreram 31 germinações do grupo teste contra 12 germinações do grupo controle (Figuras 7 e 8). A referida biometria está representada na Tabela 2.

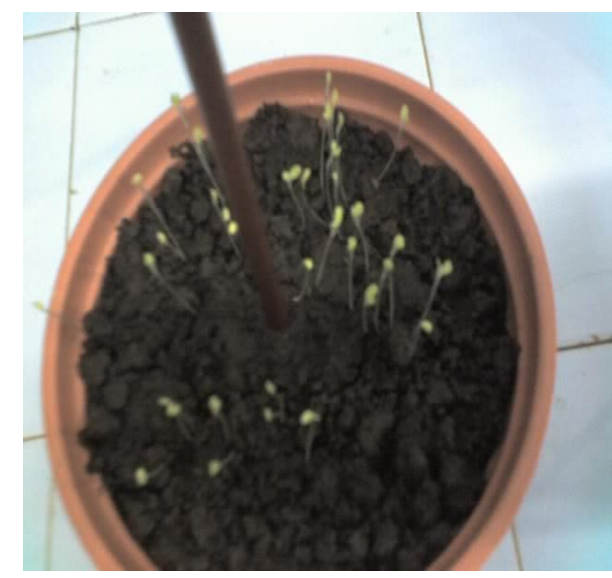

Figura 7 - Geminações do grupo teste (campo magnético voltado para cima).

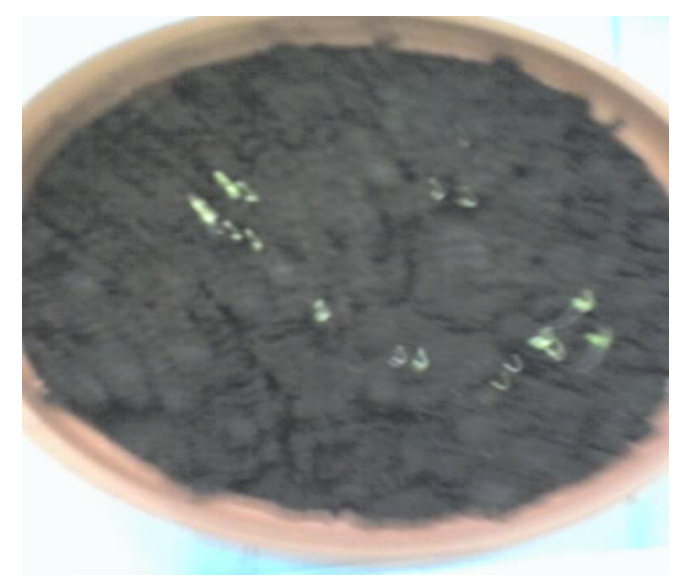

Figura 8 - Geminações do grupo controle (campo magnético voltado para cima).

Tabela 2. Experimento com o campo magnético orientado "de baixo para cima".

\begin{tabular}{|c|c|c|}
\hline Dias & $\begin{array}{c}\text { Número de } \\
\text { germinações do } \\
\text { experimento sem o } \\
\text { campo magnético }\end{array}$ & $\begin{array}{c}\text { Número de } \\
\text { germinações do } \\
\text { experimento com o } \\
\text { campo magnético }\end{array}$ \\
\hline Início & 0 & 0 \\
\hline $1^{\circ}$ dia & 0 & 0 \\
\hline $2^{\circ}$ dia & 1 & 4 \\
\hline $3^{\circ}$ dia & 3 & 25 \\
\hline $4^{\circ}$ dia & 12 & 31 \\
\hline
\end{tabular}

\section{CONSIDERAÇÕES FINAIS}

Dos resultados desta investigação e mediante análise dos mesmos, concluímos que:

- O campo magnético fraco pode potencializar a germinação das sementes de alface;

-Para a ocorrência da germinação é indispensável oxigênio, água e hormônios;

-A água possui um papel relevante na germinação do vegetal, pois a mesma juntamente com os sais minerais dissolvidos constitui a chamada seiva bruta, a qual circula na planta no sentido ascendente (da raiz para as folhas), pela zona mais interna do caule e graças à ação do campo magnético teve seu efeito potencializado, isto quando o mesmo estava direcionado de baixo para cima;

-O excesso de água prejudica a germinação e o desenvolvimento do vegetal; 
- O campo magnético direcionado de cima para baixo não potencializa o número de germinações, havendo assim um menor número de sementes germinadas no grupo teste se comparado ao grupo controle;

- O campo magnético direcionado de baixo para cima, a favor, portanto do fluxo de íons da seiva bruta, proporcionou um maior número de germinações no grupo teste;

- A corrente alternada em detrimento da corrente contínua, usada como fonte do campo no interior do solenóide, propicia um maior número de germinações.

\section{REFERÊNCIAS BIBLIOGRÁFICAS}

1. AWAD, Marcel; CASTRO, Paulo R.C. Introdução à fisiologia vegetal. São Paulo, Ed. Nobel, 1983.

2. FERRI, Mário Guimarães e vários outros autores. Fisiologia Vegetal. São Paulo, EPU: Ed. Da Universidade de São Paulo, 1979.

3. HENEINE, Ibrahim Felippe. Biofísica Básica. 2a ed. São Paulo: Atheneu, 1996.

4. LOPES, Sônia Godoy Bueno Carvalho. Bio- volume 2- Introdução ao estudo dos seres vivos. $1^{a}$ ed. São Paulo: Saraiva, 2002.

5. PAULI, Ronald Ulisses; MAUAD, Farid Carvalho; HEILMANN, Hans Peter. Física 4: Eletricidade, Magnetismo, Física Moderna e Análise Dimensional. EPU São Paulo, 19791980.

6. RAVEN, Peter H.; EVERT, Ray F.; EICHHORN, Susan E. Biologia Vegetal. 5a ed. Rio de Janeiro: Guanabara Koogan, 1996. 